\title{
ANÁLISIS DE LA SOSTENIBILIDAD EN EMPRENDIMIENTOS TURÍSTICOS UBICADOS EN ÁREAS RURALES Y NATURALES. ESTUDIOS DE CASO EN LA PROVINCIA DE ENTRE RÍOS, ARGENTINA $^{1}$
}

\author{
Claudia Toselli* \\ Universidad del Salvador. Argentina \\ https://orcid.org/0000-0002-7792-184X \\ Andrea Takáts** \\ Universidad Autónoma de Entre Ríos. Argentina \\ https://orcid.org/0000-0002-2502-7109 \\ Luciana Davi Traverso*** \\ Universidad Federal de Santa María. Brasil \\ https://orcid.org/0000-0002-4641-1038
}

\section{RESUMEN}

Este artículo surge a partir de un proyecto de investigación desarrollado en el marco de una red conformada por dos universidades argentinas y una universidad de Brasil. El objetivo principal ha sido analizar los criterios de sostenibilidad aplicados al desarrollo del turismo, tomando como estudios de caso, emprendimientos ubicados en áreas rurales y naturales de ambos países. A continuación se presentará la metodología y los resultados de cuatro

Fecha de recepción: 7 de septiembre de 2018.

Fecha de aceptación: 30 de mayo de 2019.

* Facultad de Historia, Geografía y Turismo. Universidad del Salvador. Tucumán, 1.845. CIUDAD DE BUENOS AIRES (Argentina). E-mail: claudia.toselli@usal.edu.ar

** Facultad de Ciencias de la Gestión. Universidad Autónoma de Entre Ríos. Luis N. Palma, 609. Gualeguaychú,ENTRE RÍOS (Argentina).E-mail: andreatakats@hotmail.com

*** Universidad Federal de Santa María. Avenida Roraima, 1000. Cidade universitária. Prédio 74B, sala 4312 Camobi, Santa María, RIO GRANDE DO SUL (Brasil). E-mail: luciana.traverso@ufsm.br

1 El presente artículo presenta los resultados parciales del proyecto de investigación en red: Desarrollo local en espacios rurales y naturales a través del turismo. Metodología de análisis desde la perspectiva de la sostenibilidad. La red está integrada por las siguientes universidades: Universidad del Salvador (Buenos Aires, Argentina); Universidad Autónoma de Entre Ríos (Sede Gualeguaychú, Argentina); Universidad Federal de Santa María (Brasil). El equipo de investigación estuvo conformado por: Claudia Toselli (USAL - Dirección del proyecto); Andrea Takáts (UADER - Co-dirección); Guisele Martins Guimarães (UFSM - Co-dirección). Equipo de investigación: Márquez, G.; Cardoso da Silveira, P.; Traverso, L.; Ribeiro, M.; López, M.; Ceretta, C.; Pons, M.; Bastarz, C.; Flores dos Santos, V.; Grimaldi, C.; Bonaglia, B.; Goldaracena, M.; dos Santos, S. 
sitios seleccionados en la provincia de Entre Ríos, Argentina, en los cuales se aplicó un instrumento que incluye indicadores relativos a la Gestión Sostenible, Socioeconómicos, de Patrimonio Cultural, y Ambiental.

Palabras clave: Criterios de sostenibilidad; áreas rurales; áreas naturales; Argentina.

\title{
Analysis of sustainability in touristsites located in rural and natural areas. Case stu- dies in the province of Entre Ríos, Argentina
}

\begin{abstract}
This article is about a research project developed within the framework of a network formed by two Argentine universities and one university of Brazil. The main objective has been to analyze the sustainability criteria applied to the development of tourism, taking as case studies, tourist private management sites located in rural and natural areas of both countries. It will be developed the methodology and results of four selected sites in Entre Ríos province, Argentina, where an instrument that includes indicators related to sustainable management, socioeconomic, cultural heritage, and environment was applied.
\end{abstract}

Key words: Sustainability criteria; rural areas; natural areas; Argentina.

\section{INTRODUCCIÓN}

La Universidad del Salvador, la Universidad Autónoma de Entre Ríos (ambas de Argentina), y la Universidad Federal de Santa María (Brasil), conforman desde hace cinco años una red para la reflexión, discusión, análisis e investigación conjunta en el ámbito del Mercosur, en áreas de interés común como: el turismo, el medio ambiente, el desarrollo sostenible y el desarrollo local.

En esta línea, ha sido interés de las instituciones participantes profundizar en el estudio de la sostenibilidad - desde la dimensión sociocultural, ambiental y económica -, en áreas rurales y naturales donde se desarrolla el turismo, especialmente debido a la vulnerabilidad que presentan dichas áreas por ser territorios menos intervenidos por la mano del hombre y en los cuales comienzan a llegar visitantes cada vez con mayor afluencia.

Para esto, el objetivo general de este trabajo ha sido estudiar la aplicación de criterios de sostenibilidad desde la perspectiva de la gestión, lo social-económico, el patrimonio cultural y el medio ambiente, en emprendimientos turísticos ubicados en áreas rurales y naturales de Argentina (provincia de Entre Ríos) y de Brasil (Estado de Río Grande do Sul). La finalidad última de este trabajo ha sido transferir los resultados de esta investigación a los emprendimientos donde se aplicó el estudio, como también a los organismos de gestión municipal implicados en el desarrollo del turismo y las comunidades cercanas, en vistas a capitalizar saberes y enseñanzas para futuras acciones que aporten al desarrollo turístico local sostenible en el contexto de ambos países.

En particular, en este artículo se presentarán específicamente los resultados de los casos analizados en el municipio de Gualeguaychú, provincia de Entre Ríos, Argentina. 


\section{MARCO TEÓRICO}

El turismo refleja algunas cifras que permiten entender la importancia de aplicar cada vez con más frecuencia instrumentos de estudio y evaluación, ya que, por ejemplo, es un sector económico que actualmente contribuye con el 10\% del PIB mundial; produce 1 de cada 10 puestos de trabajo en el mundo; y para 2030 proyecta los 1.800 millones de turistas internacionales (OMT, 2017).

En este sentido, si bien esta actividad presenta una oportunidad para muchas comunidades cercanas a áreas naturales o rurales al poner en valor sus recursos y generar un ingreso económico, también es cierto que se ha convertido en una actividad "consumidora" de dichos recursos, produciendo impactos a veces negativos.Sin embargo, aquí interesa destacar lo expresado por Rifai (2017), quien afirma que "el número creciente de visitantes no es el enemigo. [...] El sector necesita de una regulación específica a este respecto, así como de directrices claras, pero nunca dirigidas a limitar el crecimiento. El enfoque debe centrarse en la gestión sostenible y en medidas orientadas al crecimiento sostenible que sean beneficiosas". En este sentido, establece la necesidad de promover medidas, tales como: la localización de las actividades de los visitantes; mecanismos eficaces e integrados enfocados en la gestión de visitantes en lugares turísticos; políticas que reduzcan la estacionalidad, incentivos y políticas dirigidos a reducir el consumo de energía y agua; y atender necesidades y carencias de la comunidad local.

$\mathrm{Al}$ respecto, es importante mencionar aquí que, aunque las definiciones de turismo sostenible están sujetas a ciertos reparos, ya sea por su ambigüedad, por ser conceptualmente confusas, o por abarcar sólo un aspecto de la sostenibilidad (Lim y Cooper, 2008), en general la literatura apunta al consenso de que el turismo sostenible busca justamente reducir los impactos ambientales negativos de esta actividad, al mismo tiempo que se preocupa por preservar el patrimonio cultural y, también propiciar aprendizajes que contribuyan al perfeccionamiento de las comunidades involucradas con la actividad turística (Weaver, 2005).

Pereira (2008) también defiende que, la sostenibilidad aplicada al turismo debe establecer una relación equilibrada entre la gestión eficaz de los recursos, de manera que ésta integre el desarrollo económico y los principios ambientales, culturales y sociales característicos de las localidades involucradas. Por su parte, Uzzo (2013) destaca que el turismo sostenible aprovecha los sistemas sociales existentes, así como sus interrelaciones, para aumentar el nivel de vida de las poblaciones involucradas, buscando las adaptaciones necesarias para atender las demandas de la economía de servicios, con el fin de preservar la cohesión social y el equilibrio entre los aspectos sociales, ambientales y económicos. De esta manera, la sostenibilidad turística requiere análisis, planificación y monitoreo, teniendo en cuenta aspectos desde la escala regional hasta la global, y considerando las tendencias ambientales, sociales, económicas y políticas. Por lo tanto, la sostenibilidad del turismo sólo puede ser comprendida "de manera integral, pero siempre teniendo como foco la preservación de los recursos naturales, de la cultura y de la comunidad receptora" (Mendes y Detmering, 2018).

Según Lane (1994), aunque hay dificultad para monitorear las acciones de turismo en función de la falta de información sobre la realidad social, las vivencias locales y las mediciones del impacto en el ambiente de las áreas involucradas, la adaptación de criterios de evaluación de la sostenibilidad se vuelve fundamental. Por esto, la sostenibilidad - en 
su triple dimensión económica, sociocultural y ambiental - se ha convertido en un aspecto indispensable a considerar en cualquier modelo turístico ${ }^{2}$ que quiera contribuir al desarrollo local de un territorio, teniendo en cuenta al mismo tiempo las demandas y necesidades de las comunidades residentes. Dentro de esta perspectiva, el valor estratégico del turismo como motor para la dinamización de un territorio es cada vez más analizado por organismos e instituciones, y en consecuencia cada vez se demanda más información para que esta actividad pueda representar para los territorios en el que se desarrolla, un beneficio equilibrado en sus distintos aspectos, y no una actividad destructiva y/o perjudicial para los recursos naturales, culturales y/o la propia comunidad receptora.

Así lo plantean, por ejemplo, documentos internacionales difundidos por la Organización Mundial del Turismo en conjunto con la Organización de los Estados Americanos, ó la Organización Mundial del Turismo con el Programa de Naciones Unidas para el Desarrollo (OMT-OEA, 2018; OMT-PNUD, 2017), en los cuales se establece que el turismo sostenible es una meta firme por alcanzar en el marco de la Agenda 2030 para el Desarrollo Sostenible (ONU, 2015).

No por algo la Asamblea General de las Naciones Unidas declaró el 2017 como el Año Internacional del Turismo Sostenible para el Desarrollo, estableciendo que esta declaración "aspira a impulsar cambios en las políticas, en las prácticas empresariales y en el comportamiento de los consumidores, con el objetivo de hacer del turismo un sector más sostenible que pueda contribuir a alcanzar los Objetivos de Desarrollo Sostenible (ODS)". Y para ello elaboró una Guía recomendando una serie de actividades para los gobiernos, las organizaciones internacionales, el sector privado, las ONGs, como también para las universidades (OMT, 2016). Dentro de dicha Guía se proponen cuatro líneas de actuación, donde particularmente en el contexto de este trabajo de investigación, interesa destacar la referida a "Creación y difusión de conocimientos", la cual tiene por finalidad mejorar la comprensión del turismo sostenible y promover herramientas y mecanismos para el seguimiento y la medición de los impactos del turismo.

En este contexto propone las siguientes actividades, dentro de las cuales a las universidades les corresponde:

-Llevar a cabo investigaciones sobre la relación entre turismo sostenible y el desarrollo y sobre los diecisiete ODS, así como elaborar directrices y recomendaciones prácticas para los agentes del turismo.

2 Es importante tener en cuenta que el turismo sostenible es aquel que "tiene plenamente en cuenta las repercusiones actuales y futuras, económicas, sociales y medioambientales para satisfacer las necesidades de los visitantes, de la industria, del entorno y de las comunidades anfitrionas. Las directrices para el desarrollo sostenible del turismo y las prácticas de gestión sostenible se aplican a todas las formas de turismo en todos los tipos de destinos, incluidos el turismo de masas y los diversos segmentos turísticos. Los principios de sostenibilidad se refieren a los aspectos medioambiental, económico y sociocultural del desarrollo turístico, habiéndose de establecer un equilibrio adecuado entre esas tres dimensiones para garantizar su sostenibilidad a largo plazo". Por lo tanto, el turismo sostenible debe ayudar a conservar los recursos naturales; respetar los valores tradicionales de las comunidades anfitrionas, conservar sus recursos arquitectónicos y contribuir al entendimiento y la tolerancia intercultural. Asimismo, debe asegurar una actividad económica viable a largo plazo, que reporten a todos los actores del territorio, beneficios sociales y económicos equilibrados y justos; en tanto que debe reportar también un alto grado de satisfacción a los turistas y representar para ellos una experiencia que los haga más conscientes de los problemas de la sostenibilidad y fomente en ellos prácticas turísticas sostenibles (OMT, 2019). 
-Identificar y difundir buenas prácticas y estudios de casos reales mediante publicaciones y otras herramientas de presentación.

-Participar en el desarrollo y el uso de herramientas y enfoques que faciliten la medición del turismo sostenible (p.ej. observatorios de turismo sostenible, indicadores ambientales, etc.).

-Constituir plataformas interdisciplinares para potenciar la colaboración entre el turismo y ámbitos afines (p. ej. agricultura, medio ambiente, cultura, etc.) e identificar actividades conjuntas.

Teniendo en cuenta estas prioridades establecidas a nivel internacional, y con la meta de contribuir desde la universidad en la búsqueda de soluciones y aportes con relación al desarrollo del turismo sostenible, este trabajo reafirma su finalidad principal, tal como se explica en la introducción de este artículo.

\section{METODOLOGÍA DEL TRABAJO DE INVESTIGACIÓN}

Para alcanzar el objetivo general de este proyecto, el cual ha sido estudiar la aplicación de criterios de sostenibilidad desde la perspectiva de la gestión, lo social-económico, el patrimonio cultural y el medio ambiente, en emprendimientos turísticos ubicados en áreas rurales y naturales, se desarrollaron las siguientes etapas:

-Etapa de discusión del marco teórico y revisión de documentos

En esta fase se realizó un relevamiento de fuentes secundarias para reforzar el marco teórico del proyecto. Se recopilaron y analizaron documentos de organismos y autores especialistas en medio ambiente, turismo, desarrollo sostenible y desarrollo local.

Para la elaboración del instrumento de evaluación de la sostenibilidad turística se realizó una revisión y repaso de documentos elaborados en el período 2004-2015, por organismos internacionales y/o de cooperación, en el cual se presentaban instrumentos o herramientas para medir la sostenibilidad de un sitio turístico: GSTC, 2013 ${ }^{\mathrm{a}}$ y $2013^{\mathrm{b}}$; OIT, 2005; OMT, 2004.

-Etapa de elaboración del instrumento metodológico de análisis y selección de sitios de estudio

En esta fase se elaboró de manera consensuada un instrumento metodológico para relevar los sitios seleccionados como estudios de caso. Dicho instrumento fue analizado y discutido por el equipo de investigadores de Argentina y Brasil, y adaptado para su aplicación a los casos seleccionados en ambos países.

El instrumento denominado "Ficha de relevamiento y evaluación de la sostenibilidad turística", constó de dos partes (Ver Anexo 1):

- Una primera parte donde se consignó toda la información y datos generales relativos al establecimiento estudiado, sus principales características, aspectos de accesibilidad para los visitantes en sus distintas formas, información sobre las áreas naturales (si 
correspondía), y características más relevantes del segmento de visitantes que llegan hasta el lugar.

- Una segunda parte donde se aplicaron los criterios de sostenibilidad conformada por cuatro dimensiones: Gestión Sostenible, Socio-económica, Patrimonio Cultural, y Ambiental, las cuales sumaron un total de 23 indicadores. Para esto se tomó como base el formulario propuesto por el Consejo Global para el Turismo Sostenible ${ }^{3}$ denominado Criterios Globales de Turismo Sostenible para Destinos Turísticos (GSTC, 2013a).

Cabe indicar que dentro de esta etapa, en base a las tareas de pre-relevamiento realizada por las universidades participantes, se identificaron y seleccionaron una serie de emprendimientos de turismo, tanto en Argentina como en Brasil, que estuvieran ubicados en espacios rurales y/o en áreas naturales, en las proximidades de los territorios de las universidades integrantes de la red, y que fueran de gestión privada.

En el caso de los sitios seleccionados en Argentina, se consideró además que los establecimientos tuvieran como criterio común el desarrollo de actividades turísticas, recreativas y didácticas vinculadas con tareas de granja o campo, y/o la exploración de áreas naturales protegidas ${ }^{4}$.

En particular, los sitios de estudio seleccionados en Gualeguaychú, provincia de Entre Ríos fueron los siguientes: a) Itapeby Casa de Campo; b) La Serena del Gualeyán; c) Reserva Natural Senderos del Monte; y d) Termas del Guaychú.

\section{-Etapa de trabajo de campo. Análisis de datos y procesamiento de resultados}

En esta fase se realizó el trabajo de campo a través de la aplicación del instrumento metodológico que se explicó en el punto anterior.

Posteriormente, para el análisis y procesamiento de los datos relevados se llevó a cabo un análisis comparativo de los sitios en base a cada una de las cuatro dimensiones de sostenibilidad.

Finalmente se aplicó una matriz de evaluación cuantitativa, la cual partió de la base del total de los 23 indicadores, distribuidos en las cuatro dimensiones de sostenibilidad. Estos indicadores fueron calificados a partir de una escala de valores asignada previamente (Alta: 10 puntos - cumple con el indicador; Media: 5 puntos - cumple medianamente con el indicador; Baja: 0 puntos - no cumple con el indicador/ no aplica). La valoración de los indicadores otorgada a cada indicador por sitio fue consensuada por al menos tres investigadores del equipo. La suma total de los puntajes otorgados permitió visualizar los porcentajes

3 El Consejo Global de Turismo Sostenible - ó Global Sustainable Tourism Council (GSTC) siglas en inglés - es una iniciativa internacional para el establecimiento y gestión de las normas para el turismo sostenible. El mismo está conformado por un conjunto de empresas, instituciones académicas, organismos de gobierno y otros expertos. En el marco de este organismo se ha consensuado y elaborado este instrumento que tomó como base los indicadores de desarrollo sustentable que difunde la Organización Mundial del Turismo (OMT), y a partir del mismo se establecen las bases que el turismo debe seguir para lograr un enfoque sustentable.

4 Gualeguaychú cuenta con ocho reservas naturales que suman casi 20 mil hectáreas protegidas por la Municipalidad, el Gobierno Provincial y el sector privado. Dentro de este grupo de reservas se encuentran las reservas de gestión privada de La Serena del Gualeyán, Senderos del Monte y Termas del Guaychú. Dentro de los establecimientos que realizan actividades vinculadas al quehacer rural se encuentran La Serena del Gualeyán e Itapeby. 
alcanzados por los establecimientos estudiados con respecto a los criterios de sostenibilidad en sus cuatro dimensiones, los cuales se reflejan en la Figura 6 de este artículo.

-Etapa de elaboración de recomendaciones y transferencia de resultados a los actores locales

A partir de la aplicación de los instrumentos anteriormente mencionados (ficha de relevamiento, análisis comparativo y matriz de evaluación cuantitativa), se analizaron los datos obtenidos y sobre esa base se elaboraron una serie de recomendaciones y sugerencias para ser transferidas a los gestores responsables de las áreas de turismo y medio ambiente local, y a los actores de los emprendimientos participantes del estudio (Ver apartado Nro. 6 de este artículo).

\section{ESTUDIOS DE CASO SELECCIONADOS EN LA PROVINCIA DE ENTRE RÍOS, ARGENTINA}

Los emprendimientos turísticos seleccionados para este estudio se ubican en el Municipio de Gualeguaychú, provincia de Entre Ríos, Argentina, y fueron los siguientes:

-Itapeby, una casa de campo orientada principalmente al turismo rural y complementariamente a las visitas educativas;

-La Serena del Gualeyán, un establecimiento de tipo rural, con características de granja, que además cuenta con un centro de reciclado y una reserva natural contigua;

-la Reserva Natural Senderos del Monte, un sitio dedicado íntegramente a preservar la flora y fauna nativa, que ofrece visitas educativas y recreativas; y

-Termas del Guaychú, un complejo turístico termal, con la particularidad de contar con una reserva natural protegida en el área adyacente al complejo, con acceso directo para los turistas que se alojan en el lugar.

\section{Figura 1}

\section{UBICACIÓN DE LOS SITIOS DE ESTUDIO SELECCIONADOS EN GUALEGUAYCHÚ, PROVINCIA DE ENTRE RÍOS, ARGENTINA}

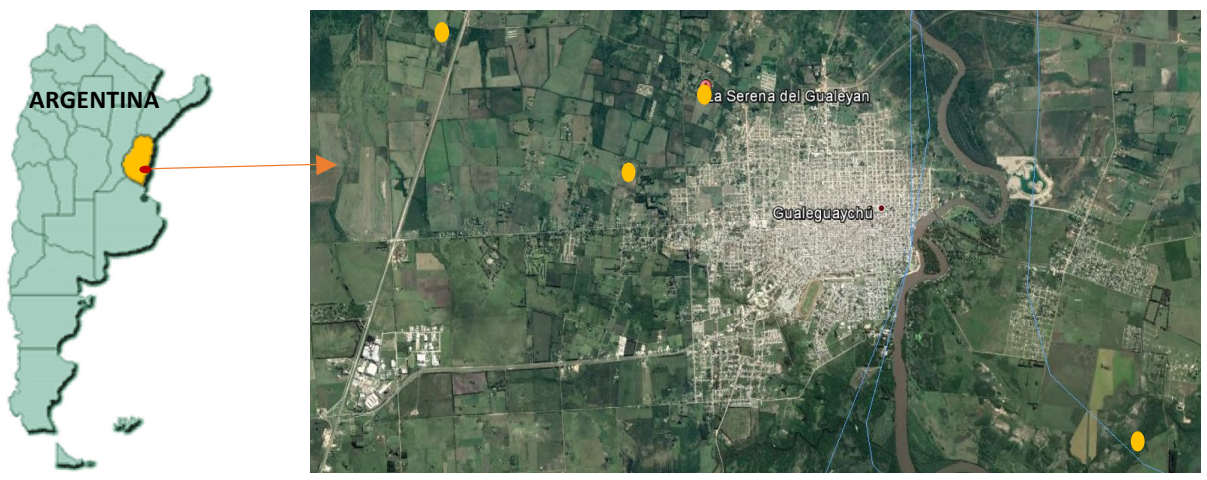

Fuente: Elaboración en base a http://www.entreriostotal.com.ar/provincia/ubicacion.htm y Google maps. 


\subsection{Estudio de caso: Itapeby, Casa de campo}

Itapeby es una chacra que ofrece alojamiento, tiene un museo tipo "pulpería", salón, establos, corrales, molino de viento, un gran quincho, parque, pileta y laguna. Tiene una capacidad máxima para alojar 14 personas. Entre las actividades ofrecidas se encuentran: cabalgatas, paseos en carro, caminatas, trekking, alimentación de animales, ordeñe, esquilado de ovejas, avistaje de flora y fauna, safaris fotográficos y contemplación del paisaje rural. También se realizan visitas para distintos niveles educativos, favoreciendo el contacto directo con los animales de campo.

En el lugar se sirven comidas típicas y en la "pulpería" se pueden observar diversos elementos de uso cotidianos utilizados en las últimas décadas en la vida diaria del campo.

\section{-Información General}

Fecha de creación del emprendimiento: El predio se adquirió en 1990 y se abrió al público como establecimiento de turismo rural en 1994.

- Cantidad de empleados: Los dueños que están a cargo del lugar son dos. Hay una persona empleada, y se contratan, en caso de ser necesario, vecinos de la zona.

- Superficie del área/lugar: Tiene una superficie de 14 hectáreas.

\section{-Información del área natural}

Categoría de manejo: El lugar está inmerso en el espacio rural, no cuenta con reserva de flora y fauna autóctona. Presenta un paisaje netamente rural-productivo, si bien existe un sector más agreste donde se encuentran especies de flora nativa.

- Características del entorno natural: Paisaje productivo rural, cercano a la zona urbana.

- Flora: Luego de unos años de rotación de cultivos se ha logrado el total del área con pastura natural, donde predomina las leguminosas y gramíneas.

- Fauna: Se encuentran perdices, teros, caranchos, loros, patos silvestres, liebres.

- Recursos hídricos: A través del aprovechamiento del escurrimiento del agua de lluvia, por declive natural del suelo, se hicieron unos seis tajamares, que permitirán el almacenamiento de unos 6 millones de litros de agua, con fines de riego.

- Recorridos existentes: No hay senderos específicos en el sitio ya que se puede recorrer el lugar libremente.

\section{-Información relativa a la accesibilidad para el turismo}

- Formas de acceso: Se accede por calle asfaltada; luego se dobla por camino de ripio, realizando un trayecto de unos $1.500 \mathrm{mts}$. hasta llegar al establecimiento.

- Días y horarios de apertura:Está abierto todo el año a excepción del período que va entre el 20 de diciembre al 20 de enero. El ingreso es solo con reserva previa. 
- Temporada: Los meses o períodos de mayor afluencia son: Semana Santa (marzo o abril, según corresponda cada año); vacaciones de invierno (mes de julio) y fines de semana largo.

- Tiempo de visita: La visita que se realiza tanto para grupo de adultos, familias, jóvenes, etc., como para colegios, tiene una duración de tres horas aproximadamente. También se puede pasar un día campo con almuerzo y merienda, extendiéndose a cinco horas.Otra posibilidad también es hospedarse en el lugar. Quienes eligen esta opción, tiene un promedio de estadía entre dos y tres días.

- Actividades que se pueden realizar in situ: Cabalgatas, paseos en carro, caminatas, trekking, alimentar animales, ordeñar, esquilar, avistaje de flora y fauna, tomar fotografías, disfrutar de la tranquilidad y silencio del campo, contemplar los atardeceres y el cielo nocturno. Dentro de las actividades dirigidas específicamente a grupos escolares - además de algunas de las mencionadas anteriormente - se encuentran: ordeñe, esquila, alimentación de animales, siembra de pastura, lombricultura, huerta y elaboración de fardos, reciclaje de residuos, trabajos de suelo, doma racional, contemplación de la naturaleza, visita a la laguna y conocer sobre las características de distintos animales.

- Facilidades de interpretación: La visita al lugar se puede realizar con el acompañamiento de sus dueños que brindan toda la información necesaria y de manera muy didáctica para comprender los usos, costumbres y tiempos de la vida de campo, como también sobre el comportamiento de los animales de granja, o los procesos y crecimiento de la flora o los cultivos. Se brinda información en español, inglés y francés.

- Costo de entrada: Se cobra un costo según el tiempo y servicios requeridos (visita con merienda, día de campo con almuerzo y merienda, o alojamiento y comidas según la cantidad de días solicitados).

- Formas de difusión del emprendimiento: El emprendimiento realiza su difusión a través del sitio web y redes sociales. Participa en charlas y eventos (particularmente en Buenos Aires), publica en guías de turismo, y se vincula con asociaciones de turismo rural, lo cual permite una difusión y promoción conjunta. También brinda entrevistas a revistas especializadas y diarios (sección de viajes o rural).

\section{-Características de los visitantes}

- Cantidad de visitantes por año: No hay un registro formal de la cantidad anual de visitantes.

- Lugar de procedencia: Proceden de la Ciudad de Buenos Aires, Gran Buenos Aires, Santa Fe, Córdoba, colegios de la provincia de Entre Ríos. Se reciben visitantes extranjeros, principalmente observadores de aves, ya que éstas abundan en la región.

- Características generales: En general son familias con niños, parejas jóvenes, también empleados de embajadas en Argentina y grupos escolares (desde nivel primario). 


\section{Figura 2 \\ VISTA DEL ESTABLECIMIENTO DE TURISMO RURAL ITAPEBY}
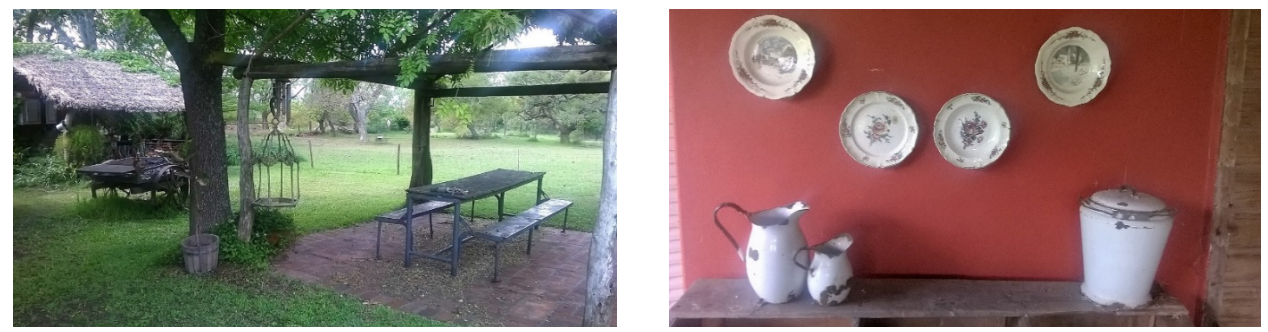

Fuente: Archivo equipo de investigación.

\subsection{Estudio de caso: La Serena del Gualeyán}

El predio se encuentra en el área no urbanizada de Gualeguaychú, zona de quintas, a 5 kilómetros del centro de la ciudad. Se accede a través de asfalto y luego por camino de ripio.

Tiene una capacidad total para alojar 35 personas. Como elementos que diferencian al lugar, el mismo posee una granja, huerta, centro de reciclado y un museo de objetos rurales antiguos (instrumentos de labranza y domésticos), además de una exposición de carros rurales.

Asimismo, desde el sitio se accede a una reserva natural. La misma tiene una superficie de 10 hectáreas de monte nativo donde se pueden observar más de 80 especies de flora autóctona y 75 especies de aves. La reserva posee también una laguna y añosos ejemplares anteriores a la fundación de la ciudad.

El emprendimiento se destaca también por haber sido certificado bajo el programa de directrices de accesibilidad por los Ministerios de Turismo de la Nación y de la Provincia de Entre Ríos, ofreciendo facilidades para personas con dificultades motoras.

\section{-Información general}

- Fecha de creación del emprendimiento: El predio se adquirió en 2004 y comenzó a funcionar en 2009. La reserva natural se abrió al público en 2012 y el museo en 2013.

- Superficie del área/lugar: El establecimiento tiene 18 hectáreas, de las cuales 10 hectáreas son de reserva natural.

- Cantidad de empleados: Hay tres personas de manera permanente a cargo del establecimiento, una de ellas para mantenimiento. El servicio de limpieza está tercerizado. En temporada alta se contratan una o dos personas más.

\section{-Información del área natural}

Categoría de manejo: Es una reserva natural privada. Cuenta con monitoreos de flora y fauna desde el año 2011 y plan de manejo. Se programa realizar los trámites de reco- 
nocimiento ante la Secretaría de Ambiente de Entre Ríos para su integración al sistema provincial de reservas naturales.

- Características del entorno natural: Los tipos de ambiente que se encuentran en la reserva son pastizal, espinal y humedal.

- Flora: Hay registradas 80 especies de plantas, con añosos ejemplares de tala y coronillo, anteriores a la fundación de la ciudad, la cual data de 1783.

- Fauna: Hay registradas 75 especies de aves, y más de 20 especies de otros animales, como por ejemplo, anfibios, reptiles, mamíferos, mariposas, etc.

- Recursos hídricos: Cuentan con una laguna que acumula agua de lluvia. Era un bañado al que profundizaron utilizando una máquina.

- Recorridos existentes: La reserva tiene dos senderos a los cuales se puede acceder solo caminando, uno corto, en las proximidades de la laguna donde se cuenta con bancos de descanso, y otro más largo que recorre toda la reserva (1.800 metros con un tiempo estimado de recorrido de dos horas).

- Cuenta con cartelería explicativa al ingreso a la reserva, incluyéndose el trazado de los recorridos de ambos senderos. Cuenta con código QR. Dentro de la reserva hay cartelería explicativa de diversas especies de flora y fauna autóctonas. Están estudiando la forma de hacer accesible el primer tramo del recorrido, hasta la laguna (unos 350 metros aproximados).

\section{-Información relativa a la accesibilidad para el turismo}

- Formas de acceso: Se llega en automóvil, por camino de asfalto y luego algunos metros por camino de ripio. También se puede acceder en ómnibus y/o combis.

- Días y horarios de apertura: El establecimiento está abierto todo el año.

- Temporada: La mayor afluencia de visitantes se da en los meses de diciembre a marzo, algunas semanas en julio (que corresponde al período de vacaciones de invierno en Argentina), y los fines de semana largo.

- Tiempo de visita: El tiempo de visita promedio es de tres y cuatro días. También se puede realizar la visita de un día, con una duración de tres a cuatro horas.

- Actividades que se pueden realizar in situ: Caminatas por la reserva de manera autoguiada o con acompañamiento de guía especializado (si se solicita previamente), visita al museo, granja y huerta.

- Facilidades de interpretación: Hay cartelería interpretativa en el sector del predio donde se realiza clasificación de residuos, y también en la reserva natural. En particular, dentro de la reserva los carteles informativos presentan código QR. Se ofrece también el acompañamiento de un guía para realizar el recorrido por la reserva, si es solicitado con anticipación.

- Costo de entrada: La visita de un día tiene un costo de entrada. Si los visitantes van a alojarse en el lugar, no se cobra entrada sino los días de alojamiento por persona.

- Formas de difusión del emprendimiento: Promocionan el lugar a través de su página web, páginas de redes sociales y otras páginas web especializadas en turismo. 
Asimismo, disponen de folletería y están asociados a FEHGRA - Federación de Empresarios Hoteleros y Gastronómicos de la República Argentina.

\section{-Características de los visitantes}

- Cantidad de visitantes por año: No hay un registro de visitantes anuales.

- Lugar de procedencia: Principalmente proceden de la Ciudad de Buenos Aires, Gran Buenos Aires y provincia de Buenos Aires. También de las provincias de Santa Fe, Córdoba y de la región patagónica. De la provincia de Entre Ríos se reciben visitantes de Paraná, Concordia, Crespo. Y de otros países, de la República Oriental del Uruguay, particularmente, de Montevideo.

- Características generales: Los que pernoctan en el lugar mayoritariamente son familias jóvenes con niños, y/o parejas jóvenes. También reciben grupos escolares de nivel primario y participantes de cursos de intérpretes naturalistas que realizan recorridos guiados por la reserva. Los observadores de aves y fotógrafos de naturaleza prefieren los recorridos autoguiados por la reserva.

Figura 3

VISTA DEL ESTABLECIMIENTO LA SERENA DEL GUALEYÁN Y RESERVA NATURAL
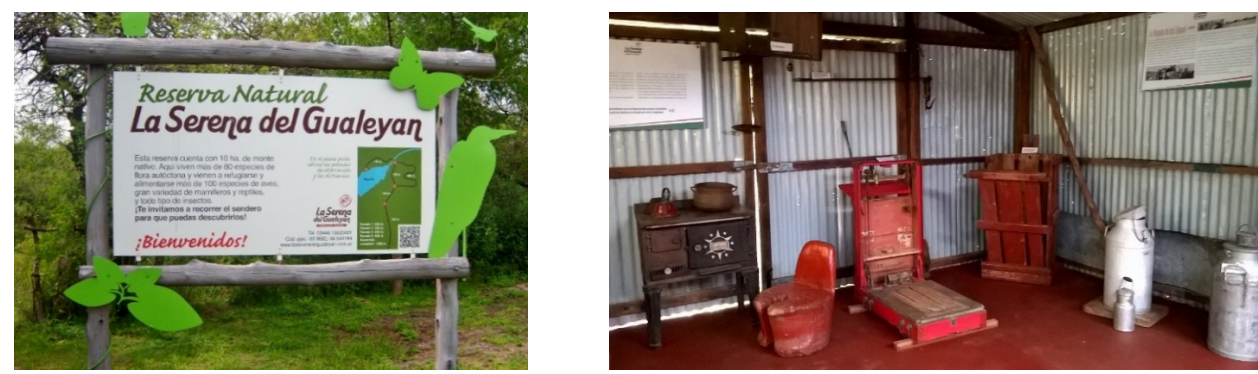

Fuente: Archivo equipo de investigación

\subsection{Estudio de caso: Reserva Natural Senderos del Monte}

Este sitio es una reserva natural de gestión privada y surge a partir de un emprendimiento familiar, con el objetivo de colaborar con el cuidado del ambiente, no sólo protegiendo la flora y fauna silvestre, sino también dándola a conocer a través de diferentes actividades.

El sitio cuenta con relevamientos de las especies nativas, y actualmente está en proceso de gestión para ser declarado área natural protegida a nivel provincial. En ella se conservan y protegen el humedal, la selva, el pastizal, el monte de espinal, el pajonal y las orillas del arroyo La Capilla. Las actividades que se pueden realizar en el lugar son fundamentalmente orientadas a la educación y sensibilización ambiental, capacitación sobre flora y fauna, conservación de especies, investigación y ecoturismo. 
Cuenta con senderos peatonales y vehiculares, áreas de descanso, observatorio de aves frente a la laguna, un mirador/mangrullo, puentes sobre el arroyo La Capilla, un refugio accesible con mesa y bancos, baños con biofiltros, horno de barro, vivero de plantas nativas, huerta orgánica y colmenas.

\section{-Información General}

- Fecha de creación del emprendimiento: El sitio es adquirido por sus dueños en 2005. En 2010 se abre al público.

- Superficie del área/lugar: 25 hectáreas.

- Cantidad de empleados: Los dueños se ocupan de distintas tareas y actividades dentro del sitio, y además hay dos empleados encargados de la limpieza, mantenimiento y cuidado del predio. Eventualmente se contrata a un guía especializado en naturaleza para realizar visitas con grupos específicos.

\section{-Información del área natural}

Categoría de manejo: Está en trámite la gestión de reserva natural privada iniciada ante la Dirección General de Recursos Naturales de la provincia de Entre Ríos, incluyendo monitoreos de especies y plan de manejo.

- Características del entorno natural: La reserva abarca 25 hectáreas en las que se conservan y protegen el humedal, la selva en galería, el pastizal, el monte de espinal, el pajonal y el arroyo La Capilla.

- Flora: Tiene un relevamiento completo de la flora existente en el lugar, en las cuatro temporadas del año. Realizan control de exóticas como el tamarindo, ligustro, mora, y hacen plantación de nativas en áreas deforestadas.

- Fauna: Se registraron un total de 148 especies de aves, 9 mamíferos, 4 reptiles, 8 anfibios, 5 peces, 63 mariposas diurnas, 154 insectos.Se encuentra en un área declarada de importancia para la conservación de las aves por Aves Argentinas y Birdlife International: ER03 Nandubaysal - El Potrero.

- Recursos hídricos: Por la reserva pasa el Arroyo La Capilla, que desemboca en el río Gualeguaychú.

- Recorridos existentes: Hay siete senderos, a tres de ellos se puede acceder con vehículos, totalizando unos 3.000 metros. Están diseñados y trazados de manera tal de presentar diferentes alternativas, según las condiciones climáticas y los requerimientos de los visitantes. A lo largo del recorrido se atraviesa el pastizal, luego el humedal y se bordea la costa del arroyo La Capilla inmerso en el monte ribereño. Hay áreas de descanso y miradores.

\section{-Información relativa a la accesibilidad para el turismo}

- Formas de acceso: Se llega en automóvil, por camino vecinal pavimentado.

- Días y horarios de apertura: Se abre al público con visitas programadas previamente. También hay días en los que programa su apertura y esto se difunde por Facebook 
y/o los medios de comunicación locales. Además, se da aviso previo a las oficinas de turismo cercanas de Pueblo Belgrano y Gualeguaychú.

- Temporada: La mayor afluencia de visitantes se da entre los meses de setiembre a diciembre.

- Tiempo de visita: La visita guiada por los senderos es de dos horas/ dos horas y media. También se programan visitas para pasar el día (con almuerzo) y tienen una duración de seis horas aproximadamente.

- Actividades que se pueden realizar in situ: Las actividades que se pueden realizar en el lugar son enfocadas principalmente a la educación ambiental, capacitación sobre flora y fauna nativas, conservación de especies, investigación y ecoturismo. Dentro de esto último, se ofrece a quienes llegan hasta el lugar el acompañamiento de un guía especializado, con avistaje de aves, visitas interpretativas de reconocimiento de flora y fauna nativa y de huellas de animales, safaris fotográficos, visitas nocturnas, juegos didáctico-educativos para niños orientados al descubrimiento y comprensión de la naturaleza, visita al vivero de plantas nativas, visita a la huerta. Hay un área núcleo en la que no se realizan visitas educativas ni recreativas.

- Facilidades de interpretación: Acompañamiento de guía naturalista en todos los recorridos. Se utiliza cartelería interpretativa al inicio de la visita, para ubicar en el contexto.

- Costo de entrada: Se cobra una entrada para hacer el recorrido guiado e incluye un refrigerio. Hay un costo especial cuando la entrada al sitio es con almuerzo incluido.

- Formas de difusión del emprendimiento: Difunde sus actividades a través de su página web y redes sociales. También a través de folletería, notas en revistas especializadas en turismo y entrevistas en medios de difusión local.

\section{-Características de los visitantes}

- Cantidad de visitantes por año: No hay un registro específico de visitantes. Aproximadamente se reciben unos 100 a 120 visitantes al año.

- Lugar de procedencia: Provienen de la Ciudad de Buenos Aires y Gualeguaychú (provincia de Entre Ríos).

- Características generales: Grupos de organizaciones de la sociedad civil especializadas en temas ambientales, como Aves Argentinas y su Escuela Argentina de Naturalistas, estudiantes universitarios (principalmente de UADER), grupos escolares de nivel secundario y primario, familias con niños. 


\section{Figura 4}

VISTA DE LA RESERVA NATURAL SENDEROS DEL MONTE
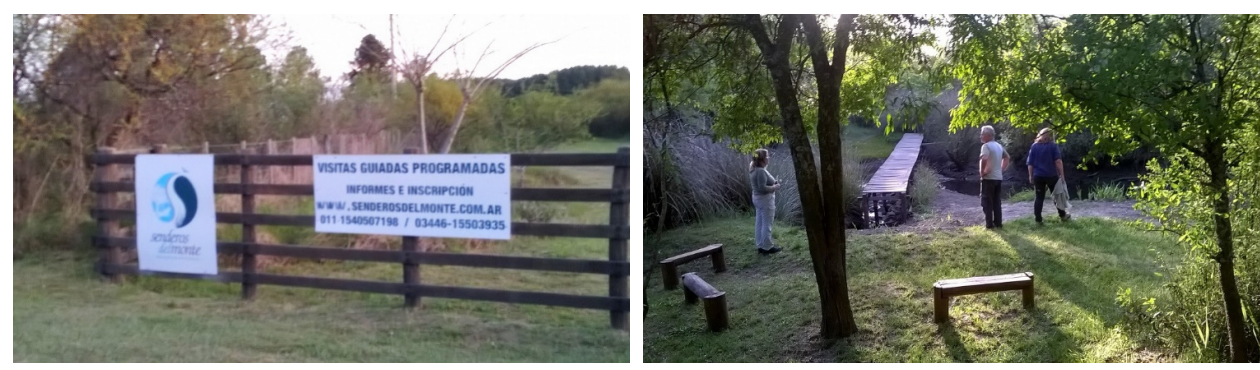

Fuente: Archivo equipo de investigación.

\subsection{Estudio de caso: Termas del Guaychú}

Este sitio es un centro termal con infraestructura y servicios turísticos (spa, bungalows, restaurant, proveeduría, plazas y venta de artesanías). Se distingue de otros centros termales de la región porque posee una reserva natural que protege la flora y fauna nativas. La misma se encuentra en un predio contiguo y se accede de forma directa desde el mismo complejo.

\section{-Información General}

- Fecha de creación del emprendimiento: La perforación termal se realizó en 1998. En 2010 se abrió al público el complejo termal y la reserva natural contigua.

- Superficie del área/lugar: Tiene unas 120 hectáreas, distribuidas en 30 hectáreas para infraestructura y servicios turísticos y 90 hectáreas destinadas a reserva natural.

- Cantidad de empleados: Hay tres socios-gerentes, 22 empleados fijos y se contratan a modo temporario entre 3 y 4 más en temporada alta. Dentro de los empleos fijos se encuentran los servicios concesionados de restaurant, proveeduría, spa y sector de venta de productos regionales.

\section{-Información del área natural}

- Categoría de manejo: Es una reserva natural privada. Cuenta con monitoreo de flora y fauna, y se está trabajando en la elaboración de un plan de manejo. Se están realizando los trámites ante la Dirección General de Recursos Naturales del Ministerio de la Producción de Entre Ríos para su integración al sistema provincial de reservas naturales.

- Características del entorno natural: La reserva natural ofrece diferentes ambientes autóctonos: monte parque, monte chaqueño, monte en galería y monte negro. Se destaca la presencia de humedales (arroyo, cañadas, lagunas y bañados). 
- Flora: En el lugar se encuentran diferentes ambientes autóctonos: Monte Parque, Monte Chaqueño, Monte en Galería y Monte Negro. Cuenta con un relevamiento de flora que hasta el momento ha registrado: 76 especies de herbáceas y 32 especies de árboles. Se continúa trabajando en el relevamiento de manera periódica.

- Fauna: Hay un registro de aves y de otras especies de animales. Las aves registradas hasta el presente son 107. Entre los animales de la reserva se pudieron observar: lobito de río, aguará popé, hurón, zorro de monte, gato montés, liebres, zorrinos y mulitas. Hay una gran presencia del ciervo Axis (especie exótica).

- Recursos hídricos: Se destaca la presencia del arroyo Gualeyán, tributario del río Gualeguaychú, y de un bañado.

- Recorridos existentes: La reserva cuenta con senderos que atraviesan los distintos ambientes. El primer tramo del recorrido puede ser transitado en auto, hasta las proximidades del arroyo Gualeyán, donde se cuenta con bancos de descanso. Otro recorrido más amplio llega hasta un bañado donde se pueden observar diversas aves. Los recorridos diurnos tienen un tiempo estimado de duración de dos horas, con interpretación de flora y fauna y los diferentes ambientes existentes. Los avistajes de aves específicos pueden durar hasta cuatro horas. Las visitas nocturnas tienen un tiempo estimado de dos horas, donde se puede apreciar la naturaleza, observar el cielo, y conocer sobre las historias y leyendas de las comunidades nativas que habitaban la zona.

\section{-Información relativa a la accesibilidad para el turismo}

- Formas de acceso: Se accede por ruta asfaltada (autovía RN 14). El medio más común para llegar hasta el lugar es en auto particular. También en micros y combis.

- Días y horarios de apertura: El complejo está abierto todo el año. El horario de atención es de 9 a 21 hs.

- Temporada: La mayor afluencia se da en los meses de enero y febrero.

- Tiempo de visita: El tiempo de visita que predomina es un fin de semana. El tiempo de recorrido por la reserva natural es de una hora, una hora y 30 minutos aproximadamente.

- Actividades que se pueden realizar in situ: Dentro de la infraestructura disponible en el sitio para realizar actividades se encuentran: cuatro piletas de agua termal y una pileta recreativa con juegos acuáticos (toboganes, mangrullo, etc.) para los más chicos. Además, se pueden realizar actividades como: caminatas, pesca recreativa, cabalgatas, recorridos en bicicletas, paseos en kayak por el arroyo Gualeyán, entre otras actividades.

Cabe indicar que la Reserva Natural que se encuentra contigua al predio y de acceso directo, se puede recorrer de manera individual o con el acompañamiento de un guía especializado en naturaleza. En los recorridos se puede realizar avistaje de aves (hay más de 100 especies diferentes), como también observar huellas de la fauna nativa, cuevas, nidos y diferentes especies de flora. Se realizan también caminatas nocturnas en luna llena. Y también hay actividades eco recreativas para niños. 
- Facilidades de interpretación: La reserva cuenta con cartelería explicativa en el área de ingreso (recepción). También en la entrada de la reserva, lo cual permite ubicar en el contexto y los distintos senderos que se pueden recorrer. Se ofrece servicio de guía especializado en naturaleza para realizar la visita a la reserva, pero es con solicitud anticipada.

- Costo de entrada: Se cobra una entrada para pasar el día, diferenciada para visitantes locales y nacionales. También existen paquetes turísticos que incluyen alojamiento y alimentación por un determinado número de días.

- Formas de difusión del emprendimiento: El sitio difunde a través de su página web y redes sociales. También participa en ferias, exposiciones, stands promocionales de la ciudad de Gualeguaychú en la Feria Internacional de Turismo (FIT) en la Ciudad de Buenos Aires, acompaña al Consejo Mixto Gualeguaychú Turismo en diferentes campañas promocionales en el país y en el Uruguay. Posee folletería. También promociona mediante entrevistas a medios gráficos, radios y otros medios de comunicación locales.

\section{-Características de los visitantes}

- Cantidad de visitantes por año: El complejo recibe entre 50.000 y 60.000 visitantes al año.

- Lugar de procedencia: Proceden de la Ciudad de Buenos Aires, Gran Buenos Aires, Rosario, y República del Uruguay.

- Características generales: Mayormente son familias con niños y parejas. También se reciben grupos de participantes de cursos de intérpretes naturalistas que realizan recorridos guiados por la reserva.

\section{Figura 5 \\ VISTA DEL ESTABLECIMIENTO TERMAS DEL GUAYCHÚ Y RESERVA NATURAL}
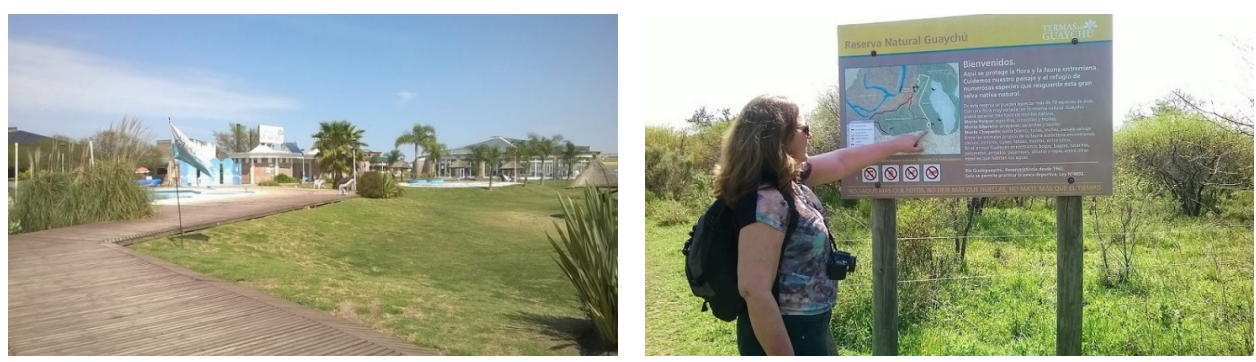

Fuente: Archivo equipo de investigación. 


\section{ANÁLISIS DE RESULTADOS}

A partir de la información recopilada y procesada, a continuación se resumen los aspectos más relevantes obtenidos del análisis de los indicadores aplicados a los cuatro sitios de estudio, en base a las dimensiones vinculadas a Gestión, Socioeconómico, Patrimonio Cultural, y Ambiental.

En particular sobre la dimensión Gestión Sostenible se observa que:

- En los cuatro sitios estudiados, tanto los administradores o responsables, como el personal reciben capacitación periódicamente sobre sus tareas y responsabilidades. Se destaca especialmente la actualización en conocimientos específicos con relación al cuidado de la flora y fauna nativa por parte del grupo que gestiona la Reserva Natural Senderos del Monte. En el caso de Itapeby, es importante mencionar que las personas que trabajan en el lugar han vivido siempre en el medio rural, y por lo tanto esto les permite transmitir sus conocimientos desde el saber empírico.

- La evaluación de la satisfacción de los visitantes y las respectivas acciones de ajuste/ corrección son aplicadas en los cuatro sitios, aunque a través de un registro cualitativo, tanto a través del monitoreo y/consulta a los visitantes de forma verbal, como a través de un libro de sugerencias (esto último se observa en la Reserva Natural Senderos del Monte y en Termas del Guaychú).

- Dos de los sitios realizan una promoción completa en cuanto a los medios de comunicación utilizados: página web, página de redes sociales, folletos, entrevistas radiales y/o televisivas en medios locales, revistas especializadas, y participación en Ferias, stands, jornadas académicas (Senderos del Monte y Termas del Guaychú). En esta difusión incluyen aspectos vinculados a las áreas naturales protegidas y las actividades que en ellas se realizan. Los otros sitios utilizan varios de estos medios para difundir sus actividades. En Itapeby no hay un área de reserva natural, pero desde los inicios, la comunicación/difusión que realizan del lugar se enmarca en los criterios del turismo responsable.

- Con respecto al diseño y construcción de edificios e infraestructura, los cuatro sitios cumplen con los requisitos de zonificación y las normas relacionadas con las áreas protegidas.

Se observa la implementación de prácticas sustentables, como por ejemplo, el uso de pantallas de energía solar, la iluminación por medio de lámparas Led, el uso de fluxer en canillas y duchas para la reducción del consumo de agua, y el empleo de biofiltros en los baños.

También en todos los sitios, en mayor o menor medida, se reutilizan y revalorizan espacios para nuevos usos aprovechando antiguas estructuras, o bien, se emplean materiales locales para la construcción y que no desentonen con el paisaje, o materiales reciclados (ej. tetrabrik para realizar techos, botellas de pet para realizar paredes). Respecto al acceso para los visitantes con necesidades especiales, todos los establecimientos contemplan la disposición de caminos, áreas de ingreso y baños especiales. Uno de los sitios cuenta con la certificación del programa de directrices de accesibilidad del Ministerio de Turismo de la Nación y del Ministerio de Turismo de la 
Provincia de Entre Ríos (La Serena del Gualeyán). Otro de los sitios está en proceso final para la aprobación de esta certificación (Termas del Guaychú).

- Con relación a las acciones de información, interpretación y sensibilización a los visitantes, acerca del paisaje natural, la cultura local y el patrimonio cultural, así como explicaciones sobre el comportamiento adecuado en estas áreas, se observan en todos los sitios, aunque hay dos donde el acompañamiento a los visitantes es personalizado (Itapeby y Senderos del Monte).

Respecto a la dimensión Socioeconómica se destaca lo siguiente:

- Los cuatro sitios participan en actividades de apoyo a la comunidad, especialmente en lo que respecta a visitas de grupos de estudios de distintos niveles en forma gratuita o a un costo accesible. También acompañan al municipio y/o a la universidad local en actividades de difusión y/o académicas relacionadas con la promoción de emprendimientos turísticos para el desarrollo local, y/o como ejemplo de acciones de preservación del patrimonio natural y cultural local.

- En todos los emprendimientos existen igualdad de condiciones para el trabajo de mujeres y hombres. También prevalece el empleo a personas residentes en la localidad o zonas próximas. Cabe destacar que uno de los establecimientos se ha empleado a una persona con capacidades especiales, y en otro de ellos se prioriza el empleo de jóvenes.

- En uno de los establecimientos se realiza una tarea de recolección diferenciada de residuos y tiene instalado un biodigestor. En otro de ellos se realiza tratamiento de aguas residuales. En otros dos sitios se realizan tareas de compostaje.

- Todos los sitios ofrecen gastronomía de producción local, y preferentemente de elaboración artesanal. En dos de los casos los productos son de elaboración propia y se complementan con otros productos de origen local.

- Los períodos de mayor afluencia de visitantes permiten generar beneficios que cubren los gastos durante la temporada baja, en todos los casos. En tres de los emprendimientos estudiados se generan ganancias. Uno solo de ellos cubre los gastos con los ingresos generados, no percibiendo rentabilidad extra.

- No se realizan informes respecto al reporte de los beneficios, no hay una política de distribución de las ganancias entre los empleados, pero tampoco de la disminución de los beneficios en periodos de baja temporada.

- El desarrollo de actividades educativas y recreativas promovida por los cuatro emprendimientos permite un mayor grado de cohesión social con la comunidad, como también el establecimiento de un vínculo con instituciones públicas locales, fortaleciendo las alianzas público-privadas y la participación en distintos eventos de interés para la localidad, contribuyendo así a los procesos de desarrollo local.

- En todos los emprendimientos se generan empleos (en mayor o menos escala) de forma directa o indirecta para los habitantes locales, pero no se puede comprobar fehacientemente en ninguno de los casos que esto haya permitido disminuir los procesos migratorios. 
En cuanto a la dimensión Patrimonio Cultural algunos aspectos a considerar son:

- Con respecto a las directrices o normas de comportamiento para las visitas a los lugares más sensibles a nivel cultural/ histórico, este criterio no aplica para ninguno de los cuatro sitios, ya que en los mismos predominan los recursos naturales por sobre los culturales, y tampoco existe ningún atractivo en esta tipología que requiera de protección específica con el fin de minimizar los impactos negativos de los visitantes.

- Solo en dos de los sitios de estudio se llevan a cabo acciones relacionadas con la preservación del patrimonio cultural tangible mueble, tratando de conservar algunas estructuras de antaño, propias de construcciones rurales.

- En los cuatros sitios estudiados - aunque en diferentes grados - se rescatan y ponen en valor manifestaciones propias de la cultura local o rural, relacionadas principalmente con el patrimonio cultural intangible. En particular, se rescata el tema de la transmisión oral respecto a las historias y costumbres de antaño en el campo, la historia contada a través de las herramientas de labranza, antiguos medios de transporte, y/o utensilios domésticos. En uno de los sitios de estudio, se transmiten leyendas locales que permiten un conocimiento diferente del patrimonio natural de la zona. En otro de los establecimientos existe un proyecto de elaborar una línea de tiempo con relación a los distintos grupos que habitaron la zona hasta el presente. Finalmente, es de mencionar que uno solo de los sitios relevados, los visitantes tienen la posibilidad de adquirir artesanías elaborados en madera, cuero, y el típico "mate".

- Los servicios de gastronomía que se ofrecen al turista valoran la tradición culinaria y los productos locales que se emplean son provenientes de la agricultura/ganadería del lugar. Solo uno de los sitios no ofrece servicio de gastronomía a los visitantes. Los otros tres establecimientos, sí lo hacen, destacando la disponibilidad de comidas típicas de campo, como el "asado", los pasteles con "mate", y las "empanadas". O bien, en uno de ellos existe la posibilidad de comer pescado de río, que está vinculado a los recursos de producción local, como también adquirir productos para llevar elaborados artesanalmente en la zona, tales como alfajores, vinos, embutidos y quesos. En otro de los sitios, cabe destacar, la existencia de productos elaborados en el propio establecimiento, y que son ofrecidos a los visitantes durante su estadía, tales como miel y té de hierbas medicinales.

Por último, en lo referente a la dimensión Ambiental, es de resaltar que:

- De los sitios estudiados, uno solo aplica criterios para el uso de ciertos productos no perjudiciales con el medio natural. El único sitio que lo hace, emplea este criterio solamente con relación al cuidado del área de la reserva natural propiamente dicha.

- Con respecto a las acciones para un consumo del agua y la energía (luz, gas) de manera responsable; y/o la utilización de energías renovables (solar, eólica, biogás), hay algunos de los sitios que por su magnitud emplean algunas de estas acciones porque al mismo tiempo que ayuda a minimizar los impactos en los recursos no renovables, también representa una disminución en los gastos de servicios (ej. agua o electricidad).

- Sobre el tratamiento o disposición especial de las aguas residuales, residuos sólidos, y/o residuos peligrosos asociados a los visitantes (ej. baterías, pilas), se observa 
positivamente que en todos los casos, ya sea en mayor o menor medida, se implementan acciones de este tipo. Cabe destacar que en dos de los sitios estudiados se brinda además información a los visitantes sobre este tema, lo cual permite generar un efecto multiplicador y una mayor sensibilización al respecto.

- El criterio sobre las prácticas para minimizar la contaminación sonora no aplica porque las actividades que se realizan en los cuatro sitios estudiados no promueven este tipo de contaminación. Al respecto, cabe destacar que, uno de los sitios emplea una práctica concreta, que es la utilización de vegetación como filtro para amortiguar el sonido de los autos que pasan por el camino asfaltado sobre el cual se encuentra el lugar. En los otros casos, los sitios se hallan relativamente lejos de rutas o calles transitadas por automóviles, por lo cual no presentan problemas con relación a este tipo de impacto.

- Con relación a las acciones para proteger y conservar las especies (flora/fauna) autóctona, como así también evitar la introducción de especies exóticas en dos de los sitios, se observa que se cumple este indicador en su totalidad. En los otros dos sitios se observa un nivel adecuado de conciencia con respecto a estos temas.

- En los cuatro establecimientos se apoya y contribuye a la conservación de la biodiversidad, incluyendo áreas naturales protegidas. Hay uno de ellos que particularmente centra sus actividades en la conservación de las distintas especies que habitan el lugar y la protección del área natural como un fin en sí mismo, más allá de que se ofrece como "producto turístico" para los visitantes (Reserva Natural Senderos del Monte).

A continuación, a partir de la matriz de evaluación cuantitativa aplicada (tal como se explicó en el punto 3 de este artículo) se arribó al siguiente resultado:

\section{Figura 6 \\ INDICADORES DE SOSTENIBILIDAD: PORCENTAJES ALCANZADOS POR CADA SITIO DE ESTUDIO}

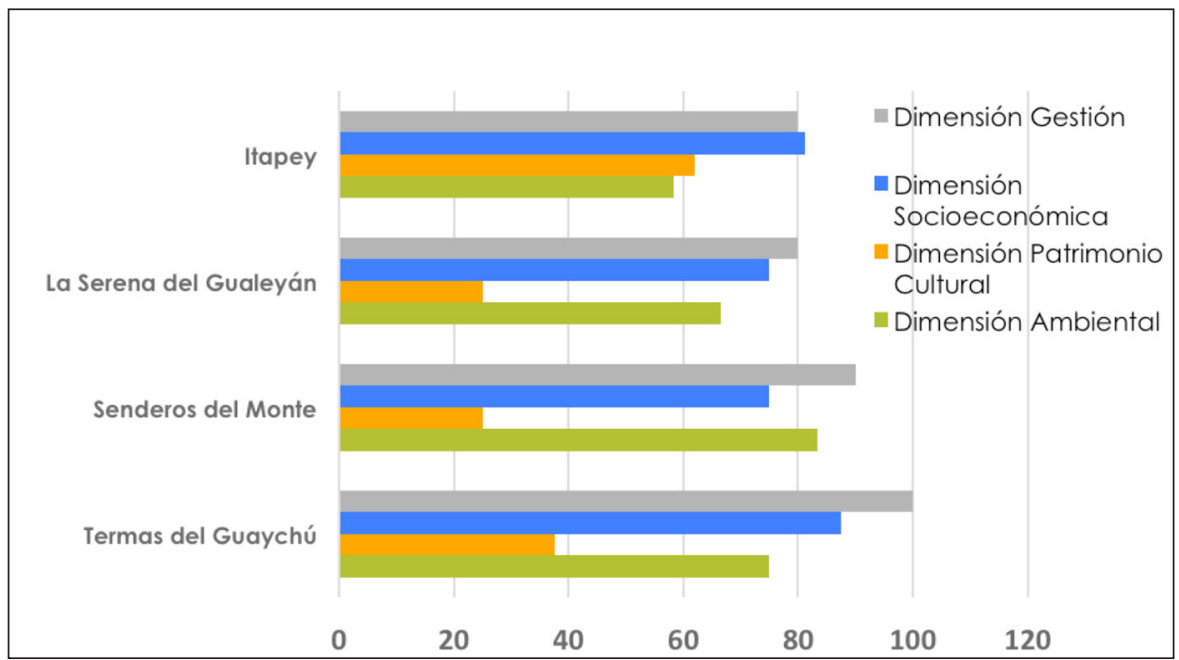


En base a la aplicación de dicho instrumento y su respectivo procesamiento y análisis se concluyó que los sitios estudiados en Entre Ríos, Argentina, alcanzaron un 70\% ó más en el cumplimiento de las dimensiones de Gestión Sostenible, Socioeconómica y Ambiental. Con respecto a la dimensión Patrimonio Cultural, la suma de los indicadores apenas superó el $35 \%$.

Los indicadores de sostenibilidad analizados en el conjunto de los cuatro sitios de estudio que alcanzaron los mayores porcentajes fueron:

- Dentro de la dimensión de Gestión Sostenible: se destaca que el personal recibe capacitación periódicamente sobre sus tareas y responsabilidades, y que son implementadas acciones de información, interpretación y sensibilización a los visitantes.

- Acerca de la dimensión Socio-económica se observó que ampliamente los emprendimientos apoyan de manera activa las iniciativas y desarrollo social de la comunidad (incluyendo, educación, formación, salud, limpieza, etc.); ofrecen igualdad de oportunidades de empleo e ingresos para mujeres, jóvenes, minorías y la población local. Asimismo, las actividades que realiza no impactan en los servicios básicos de las comunidades próximas, y que existe un período del año de mayor afluencia turística que permite obtener ganancias y atenuar los períodos de menor cantidad de visitantes.

- Respecto de la dimensión de Patrimonio Cultural, el único indicador que se observó en mayor o menor medida en todos los establecimientos fue el relativo al rescate y valoración de ciertas manifestaciones propias de la cultura local/rural, ya sea artesanías, tradición oral, mitos y leyendas, gastronomía, etc.

- En cuanto a la dimensión Ambiental, en los cuatro establecimientos se identificó positivamente que existe un tratamiento o disposición especial de las aguas residuales, de residuos sólidos y/o peligrosos; como así también que se favorecen las prácticas para minimizar la contaminación sonora.

\section{PRINCIPALES APORTACIONES DE ESTE ESTUDIO Y CONCLUSIONES}

La finalidad de este proyecto ha sido estudiar la sostenibilidad en sus diferentes dimensiones (Gestión, Socioeconómica, Patrimonio Cultural y Ambiental) en emprendimientos turísticos ubicados en áreas rurales y naturales de Argentina y Brasil. En particular, este artículo se ha enfocado a mostrar en detalle los estudios de caso de cuatro sitios identificados en el municipio de Gualeguaychú, provincia de Entre Ríos, Argentina.

A partir de la elaboración de un instrumento específico y su aplicación a los establecimientos seleccionados (Itapeby, La Serena del Gualeyán, Senderos del Monte y Termas del Guaychú), surgen algunas recomendaciones a transferir a los responsables de los establecimientos, como también a los gestores locales vinculados con el desarrollo del turismo a nivel municipal, las cuales constituyen el principal aporte de este proyecto.

En este sentido,las sugerencias más relevantes para los establecimientos de Gualeguaychú, provincia de Entre Ríos, son:

En cuanto a la dimensión Gestión se sugiere evaluar de manera sistematizada la satisfacción de los visitantes, y en caso de ser necesario, implementar acciones de ajuste/ corrección sobre la base de estas encuestas o sondeos de opinión. 
- Respecto la dimensión Socioeconómica sería importante ofrecer más productos basados en los recursos naturales y la cultura del lugar/región, tanto de producción propia como de otros productores o artesanos locales, ya sea alimentos, bebidas, artesanías, etc.

Asimismo, tener un reporte de rentabilidad que permita adoptar iniciativas concretas en aquellas etapas del año que disminuyen ó aumentan los beneficios, y así minimizar el impacto o los efectos de la estacionalidad de la actividad turística con relación a los ingresos económicos.

- Acerca de la dimensión Patrimonio Cultural se considera relevante contribuir a la protección y preservación del patrimonio cultural intangible, por ejemplo, a través del rescate de la tradición oral, mitos y leyendas, historias asociadas a la vida rural o a las áreas naturales, ya que esto le podría otorgar un contenido o valor agregado alos establecimientos visitados.

- Sobre la dimensión Ambiental, si bien en algunos de los sitios ya se están implementando, algunas acciones que se enuncian a continuación son:

-Establecer criterios de uso y compra de productos no perjudiciales para el medio ambiente, reutilizables, retornables o reciclables.

-Llevar a cabo acciones efectivas orientadas al consumo responsable del agua y la energía, como también a la utilización de energías renovables (calefones solares, energía eólica, biogás).

-Implementar acciones para proteger y conservar las especies (flora/fauna) autóctona, al tiempo que se toman medidas para evitar la introducción de especies exóticas.

Para finalizar es importante tener en cuenta que el turismo promueve actualmente el desarrollo de muchos territorios y cada año el número de turistas crece de manera sostenida. De allí que las mejoras en la planificación y gestión del sector deben ser clave para que esta actividad genere beneficios para las comunidades donde se desarrolla. De no ser así, el turismo será visto como un fenómeno negativo originando efectos contrarios a los esperados. Por esto, tanto desde el área pública como privada del turismo, se debe tener cada vez más conciencia en implementar acciones, instrumentos y/o herramientas que le permitan mantener la sostenibilidad en el tiempo de los destinos, y demostrar así que el turismo no es un "enemigo", sino sólo cuando se llevan a cabo gestiones inadecuadas.

Esta propuesta metodológica y su posterior aplicación aspiró a realizar un aporte a los gestores locales y emprendedores turísticos del municipio de Gualeguaychú, y también ayudar a promover decisiones más acertadas con relación al desarrollo del turismo sostenible. El empleo de ciertos instrumentos que permitan revisar y analizar las acciones que se están llevando a cabo en materia socioeconómica, de gestión, ambiental y de patrimonio cultural, ayudarán a tener una visión más clara del camino recorrido, de los ajustes que son necesarios hacer, y de las acciones o iniciativas que pueden implementarse para la sostenibilidad desde una perspectiva más clara. Sobre esta base, a través de pequeñas acciones se pueden fomentar grandes diferencias en favor de la implementación de un turismo de calidad en estas diferentes dimensiones, y constituir el primer paso para mejorar la gestión, la organización y la planificación de la actividad turística. 


\section{BIBLIOGRAFÍA}

GSTC. GLOBAL SUSTAINABLE TOURISM COUNCIL (2013a): Criterios Globales de Turismo Sostenible para Destinos Turísticos, Versión 1.0, noviembre de 2013. Disponible en: http://www.gstcouncil.org/en/docs/file/401-spanish-criteria-for-destinations.html GSTC. GLOBAL SUSTAINABLE TOURISM COUNCIL (2013b): Critérios do Conselho Global de Turismo Sustentável e indicadores de desempenho sugeridos para Hotéis e Operadores Turísticos, Versión 2.0, diciembre 2013. Disponible en: http://www. gstcouncil.org/en/docs/file/402-portuguese-criteria-for-hotels-and-tour-operators.html

HUERTA GARCÍA, M. y SÁNCHEZ CRISPÍN; A. (2011): "Evaluación del potencial ecoturístico en áreas naturales protegidas del municipio de Santa María Huatulco, México", Cuadernos de Turismo, no 27, pp. 541-560.

LANE, B. (1994): “What is rural tourism?”, Journal of Sustainable Tourism, vol. 2 (1-2), pp. 7-21

LIM, C.C. y COOPER, C. (2008): "Beyond sustainability: optimising island tourism development", International Journal of Tourism Research, vol. 11 (1), p. 89-103.

MÁRQUEZ, G., TOSELLI, C., VILLANUEVA, R., TAKÁTS, A., CARDOSO DA SILVEIRA, P., MARTINS GUIMARÃES, G., FLORES DOS SANTOS, V. y DE OLIVEIRA VENTURINI, F. (2015): Criterios de sustentabilidad en áreas naturales y rurales orientados al desarrollo local y la aplicación de buenas prácticas en turismo. USAL-UADER-UFSM, Ediciones Universidad del Salvador, Buenos Aires.Disponible en: http://racimo. usal.edu.ar/3705/1/Publicacion_final_CritSust_sp_USAL-UADER-UFSM_def.pdf

MENDES, F.C. y DETMERING, P.H.M. (2018): "Turismo sustentável na comunidade chã de Jardim em Areia/Pb", Applied Tourism, vol. 3(1), pp. 72-92.

OIT. Organización Internacional del Trabajo (2005): Pautas metodológicas para el análisis de experiencias de turismo comunitario, Serie Red de Turismo Sostenible Comunitario para América Latina (REDTURS), SEED: Documento de trabajo núm. 73, Ginebra, Suiza.

OIT-CIF. Organización Internacional del Trabajo-Centro Internacional de Formación (2004): Turismo y desarrollo local sostenible: elementos para un debate. Noticias Delnet, Revista electrónica del Programa Delnet de Desarrollo Local, no 34 .

OMT. Organización Mundial Del Turismo (2015): Tourism and the Sustainable Development Goals, Madrid. Disponible en: http://icr.unwto.org/publication/tourism-andsustainable-development-goals

OMT. Organización Mundial del Turismo (2016): 2017 Año Internacional del Turismo Sostenible para el Desarrollo, Guía para celebrarlo juntos, Ed. UNWTO Publicaciones, Madrid. Disponible en: http://www.tourism4development2017.org/wp-content/ uploads/2017/04/brochure_iy2017_es_web_new.pdf

OMT. Organización Mundial del Turismo (2017): Panorama OMT del turismo internacional - Edición 2017. Ed. UNWTO Publicaciones, Madrid. Disponible en: https:// www.e-unwto.org/doi/pdf/10.18111/9789284419043

OMT. Organización Mundial del Turismo (2017): Portal del Año Internacional del Turismo Sostenible para el Desarrollo. Disponible en: http://www.tourism4development2017. org/es/ 
OMT. Organización Mundial del Turismo (2019): Definición de Turismo Sostenible. Disponible en: http://sdt.unwto.org/es/content/definicion

OMT. Organización Mundial del Turismo (2004): Indicators of Sustainable Development for Tourism Destinations: A Guidebook, Madrid, España.

OMT-OEA. Organización Mundial del Turismo y Organización de Estados Americanos (2018). Tourism and the Sustainable Development Goals - Good Practices in the Americas, UNWTO, Madrid. Disponible en:https://doi.org/10.18111/9789284419685

OMT-PNUD. Organización Mundial del Turismo y Programa de Naciones Unidas para el Desarrollo (2017): Tourism and the Sustainable Development Goals - Journey to 2030, UNWTO, Madrid.https://www.e-unwto.org/doi/pdf/10.18111/9789284419401

ONU. Organización de Naciones Unidas (2015): Objetivos de Desarrollo Sostenible. Disponible en: http://www.un.org/sustainabledevelopment/es/objetivos-de-desarrollosostenible/

ONU (2015): Transforming our world: The 2030 Agenda for Sustainable Development. A/RES/70/1. Disponible en: https://sustainabledevelopment.un.org/content/documents/21252030\%20Agenda\%20for\%20Sustainable\%20Development\%20web.pdf

PEREIRA, L.G. (2008): Síntese dos Métodos de Pegada Ecológica e Análise Emergética para Diagnóstico da Sustentabilidade de Países: O Brasil como estudo de caso. Tese Doutorado em Engenharia de Alimentos, Campinas, Universidade Estadual de Campinas.

RIFAI, T. (2017): “Turismo: el crecimiento no es el enemigo sino la gestión insostenible”, en UNWTO News, ${ }^{\circ}$ 66, 24 de agosto de 2017. Disponible en: http://media.unwto. org/es/content/unwto-news-66

TÁKATS, A. y TOSELLI, C. (2016): "Estudio ambiental y turístico de la Reserva Natural Las Piedras (Gualeguaychú, provincia de Entre Ríos, Argentina)”, Tiempo de Gestión, año $12, n^{\circ} 21$, pp. 15-31.

UZZO, S.M. (2013): "Puntacana Ecological Foundation and the scaling of sustainable tourism development”, Ecology and Society, vol. 18 (4). https://ecologyandsociety. org/vol18/iss4/art73/

WEAVER, D.B. (2005): "Comprehensive and minimalist dimensions of ecotourism", enAnnals of Tourism Research, vol. 32 (2), pp. 439-455.

\section{SITIOS WEB CONSULTADOS}

Establecimiento Itapeby. http://www.itapeby.com/

Establecimiento Termas del Guaychú.http://termasdelguaychu.com.ar/ubicacion

Gobierno de la provincia de Entre Ríos, Secretaría de Medio Ambiente.http://www. entrerios.gov.ar/ambiente/userfiles/files/archivos/Plan\%20Girsu/B\%20-\%20 Gesti\%C3\%B3n\%20de\%20Residuos/9\%20-\%20Relevamiento\%20girsu/Fichas\%20 Tecnicas/Gualeguaychu.pdf

Municipalidad de Gualeguaychú. http://gualeguaychu.gov.ar/noticia/7350-ocho-reservasnaturales-para-disfrutar-de-la-naturaleza-en-gualeguaychu

Reserva Natural Senderos del Monte.http://senderosdelmonte.com.ar/inicio.html 


\section{Anexo I \\ FICHA DE RELEVAMIENTO Y EVALUACION DE LA SOSTENIBILIDAD TURISTICA PARA EMPRENDIMIENTOS TURÍSTICOS UBICADOS EN AREAS RURALES Y NATURALES}

\begin{tabular}{|c|c|}
\hline DENOMINACIÓN: (nombre del empren & \\
\hline País: & \multirow{7}{*}{$\begin{array}{l}\text { (Plano de ubicación del emprendimiento } \\
\text { y/o imagen satelital del sitio donde se } \\
\text { encuentra el atractivo) }\end{array}$} \\
\hline Provincia: & \\
\hline Departamento: & \\
\hline Localidad: & \\
\hline Dirección postal: & \\
\hline Nombre del responsable a cargo: & \\
\hline Datos de contacto: (Tel./e-mail/sitio web): & \\
\hline
\end{tabular}

\begin{tabular}{|l|l|}
\hline INFORMACIÓN GENERAL & \\
\hline Fecha de creación del emprendimiento: & \\
\hline Superficie del área/lugar: & \\
\hline Cantidad de empleados: & \\
\cline { 1 - 1 } & \\
Descripción: (características más relevantes del lugar) \\
\end{tabular}

\begin{tabular}{|l|l|}
\hline INFORMACION RELATIVA A LA ACCESIBILIDAD PARA EL TURISMO \\
\hline Formas de acceso: & \\
\hline Días y horarios de apertura: & \\
\hline $\begin{array}{l}\text { Temporada: (época del año de mayor afluencia de } \\
\text { visitantes) }\end{array}$ & \\
\hline Tiempo de visita: (aproximado) & \\
\hline Actividades que se pueden realizar in situ: & \\
\hline $\begin{array}{l}\text { Facilidades de interpretación: (folletos, servicio de } \\
\text { guías, cartelería, etc.) }\end{array}$ & \\
\hline Costo de entrada: & \\
\hline Formas de difusión del emprendimiento: & \\
\hline
\end{tabular}




\begin{tabular}{|l|}
\hline $\begin{array}{l}\text { INFORMACIÓN AREA NATURAL (completar esta información solo si el emprendimiento } \\
\text { incluye un área natural) }\end{array}$ \\
\hline Categoría de manejo: (Reserva municipal, Reserva privada, Refugio de vida silvestre, etc.) \\
\hline Geomorfología (incluir tipo de ambiente, si corresponde): \\
\hline Flora: \\
\hline Fauna: \\
\hline Recursos hídricos: \\
\hline Clima: \\
\hline Recorridos existentes: \\
\hline
\end{tabular}

\begin{tabular}{|l|l|}
\hline CARACTERISTICAS DE LOS VISITANTES \\
\hline Cantidad de visitantes por año: & \\
\hline Lugar de procedencia: & \\
\hline Características generales: & \\
\hline
\end{tabular}

\begin{tabular}{|c|l|l|}
\hline \multicolumn{3}{|c|}{ SECCION A: DIMENSION GESTION SOSTENIBLE } \\
\hline $\mathbf{N}^{\circ}$ & \multicolumn{1}{|c|}{ INDICADOR } & \multicolumn{1}{|c|}{ DESCRIPCION } \\
\hline A.1 & $\begin{array}{l}\text { El personal recibe capacitación periódicamente sobre sus tareas y } \\
\text { responsabilidades. }\end{array}$ & \\
\hline A.2 & $\begin{array}{l}\text { Es evaluada la satisfacción de los visitantes y se implementan } \\
\text { acciones de ajuste/corrección. }\end{array}$ & $\begin{array}{l}\text { El material promocional es claro y completo en lo que dice } \\
\text { respecto al emprendimiento, sus productos y servicios, incluyendo } \\
\text { los aspectos vinculados a la sostenibilidad. }\end{array}$ \\
\hline A.4 & $\begin{array}{l}\text { Planeamiento, diseño, construcción, renovación...de edificios e } \\
\text { infraestructura incluidos senderos, servicios generales y señalética: } \\
\text { a) cumplen con los requisitos de zonificación y las normas } \\
\text { relacionadas con las áreas protegidas y las consideradas como } \\
\text { patrimonio natural y cultural, } \\
\text { b) se implementan prácticas y materiales sustentables localmente } \\
\text { apropiados, } \\
\text { c) en caso de ser necesario, se brinda un acceso adecuado para } \\
\text { visitantes con necesidades especiales. }\end{array}$ \\
\hline A.5 & $\begin{array}{l}\text { Son implementadas acciones de información, interpretación y } \\
\text { sensibilización a los visitantes sobre: el paisaje natural, la cultura } \\
\text { local y el patrimonio cultural, así como explicaciones sobre el } \\
\text { comportamiento adecuado en estas áreas. }\end{array}$ & \\
\hline
\end{tabular}




\begin{tabular}{|c|c|c|}
\hline \multicolumn{3}{|c|}{ SECCION B: DIMENSION SOCIOECONÓMICA } \\
\hline $\mathbf{N}^{\circ}$ & INDICADOR & DESCRIPCION \\
\hline B.1 & $\begin{array}{l}\text { El emprendimiento apoya activamente las iniciativas de desarrollo } \\
\text { social de la comunidad, incluyendo, entre otros, educación, } \\
\text { formación, salud, limpieza, etc. }\end{array}$ & \\
\hline B. 2 & $\begin{array}{l}\text { El emprendimiento ofrece igualdad de oportunidades de empleo e } \\
\text { ingresos para mujeres, jóvenes, minorías (ej. discapacitados) y la } \\
\text { población local (independientemente de su raza, religión o nivel } \\
\text { económico), incluso en puestos de dirección, limitando por otra } \\
\text { parte el trabajo infantil. }\end{array}$ & \\
\hline B. 3 & $\begin{array}{l}\text { Las actividades del emprendimiento no impactan en los servicios } \\
\text { básicos como alimento, agua, energía, salud o limpieza en las } \\
\text { comunidades próximas. }\end{array}$ & \\
\hline B.4 & $\begin{array}{l}\text { El emprendimiento ofrece productos sustentables basados en la } \\
\text { naturaleza y la cultura del lugar/región, tanto de producción propia } \\
\text { como de otros productores o artesanos locales. Estos productos } \\
\text { pueden incluir alimentos, bebidas, artesanías, etc. }\end{array}$ & \\
\hline B.5 & $\begin{array}{l}\text { Existe un período del año de mayor afluencia turística y ocupación } \\
\text { que permite obtener ganancias y atenuar los períodos de menor } \\
\text { cantidad de visitantes. }\end{array}$ & \\
\hline B.6 & $\begin{array}{l}\text { Con respecto a la rentabilidad de la actividad indicar si hay reportes } \\
\text { de los beneficios. En caso afirmativo, indicar cómo se realizan } \\
\text { estos informes. Existe un reparto de los beneficios con el equipo } \\
\text { de trabajo. Se adoptan iniciativas en relación al aumento ó la } \\
\text { disminución de los beneficios en periodos de baja o alta temporada. }\end{array}$ & \\
\hline B.7 & $\begin{array}{l}\text { El turismo promueve un mayor grado de cohesión social en } \\
\text { la comunidad a partir del fortalecimiento del vínculo con las } \\
\text { autoridades locales, u otros organismos/ instituciones. O bien en } \\
\text { la participación de procesos participativos, fortaleciendo aspectos } \\
\text { solidaridad y confianza en la comunidad. }\end{array}$ & \\
\hline B. 8 & $\begin{array}{l}\text { El emprendimiento genera trabajo (directo e indirecto) e ingresos } \\
\text { que permiten disminuir los procesos de inmigración de la } \\
\text { comunidad. }\end{array}$ & \\
\hline
\end{tabular}

\begin{tabular}{|c|l|c|}
\hline \multicolumn{3}{|c|}{ SECCION C: DIMENSION PATRIMONIO CULTURAL } \\
\hline $\mathbf{N}^{\circ}$ & \multicolumn{1}{|c|}{ INDICADOR } & DESCRIPCION \\
\hline C.1 & $\begin{array}{l}\text { El emprendimiento sigue las directrices establecidas o un código } \\
\text { de comportamiento para las visitas a los sitios más sensibles a nivel } \\
\text { cultural o histórico, con el fin de minimizar el impacto negativo y } \\
\text { maximizar la satisfacción de los visitantes. }\end{array}$ & $\begin{array}{l}\text { lel patrimonio cultural tangible: sitios y edificios históricos, } \\
\text { arqueológicos, paleontológicos y culturales importantes en la } \\
\text { región. }\end{array}$ \\
\hline C.2 & $\begin{array}{l}\text { El emprendimiento contribuye a la protección y preservación } \\
\text { and }\end{array}$ \\
\hline
\end{tabular}




\begin{tabular}{|l|l|l|}
\hline C.3 & $\begin{array}{l}\text { El establecimientorescata,valora y potenciaalgunas manifestaciones } \\
\text { propias de la cultura local o rural, como artesanías, decoración, } \\
\text { celebraciones festivas, música, danza, vestimenta, tradición oral, } \\
\text { gastronomía, mitos y leyendas, etc. (patrimonio cultural intangible). }\end{array}$ & \\
\hline C.4 & $\begin{array}{l}\text { Los servicios de gastronomía que se ofrecen al turista valoran la } \\
\text { tradición culinaria y los productos locales que se emplean son } \\
\text { provenientes de la agricultura/ganadería del lugar. }\end{array}$ & \\
\hline
\end{tabular}

\begin{tabular}{|c|c|c|}
\hline \multicolumn{3}{|c|}{ SECCION D: DIMENSION AMBIENTAL } \\
\hline $\mathbf{N}^{\circ}$ & INDICADOR & DESCRIPCION \\
\hline D.1 & $\begin{array}{l}\text { Existe un criterio de uso/compra de productos no perjudiciales para } \\
\text { el medio ambiente, reutilizables, retornables o reciclables. }\end{array}$ & \\
\hline D.2 & $\begin{array}{l}\text { Se implementan acciones para un consumo del agua y la energía } \\
\text { (luz, gas) de manera responsable. Y/o utilización de energías } \\
\text { renovables (tanto energía como calefones solares), eólica, biogás. }\end{array}$ & \\
\hline D.3 & $\begin{array}{l}\text { Existe un tratamiento o disposición especial de las aguas } \\
\text { residuales,residuos sólidos, y/o residuos peligrosos asociados a los } \\
\text { visitantes (ej. baterías, pilas). }\end{array}$ & \\
\hline D.4 & Se favorecen prácticas para minimizar la contaminación sonora. & \\
\hline D.5 & $\begin{array}{l}\text { Se implementan acciones para proteger y conservar las especies } \\
\text { (flora/fauna) autóctona, al tiempo que se toman medidas para evitar } \\
\text { la introducción de especies exóticas. }\end{array}$ & \\
\hline D.6 & $\begin{array}{l}\text { El emprendimiento apoya y contribuye a la conservación de la } \\
\text { biodiversidad, incluyendo áreas naturales protegidas y/o áreas de } \\
\text { gran biodiversidad. }\end{array}$ & \\
\hline
\end{tabular}

Fuente: Elaborado en base a GSTC (2013 $\left.{ }^{\mathrm{a}}\right)$.

\section{Observaciones/notas:}

Fecha: (día/mes/año)

Relevó: (nombre y apellido)

Fotos: (nombre y apellido) 
